\title{
BMJ Open Change of access to emergency care in a repopulated village after the 2011 Fukushima nuclear disaster: a retrospective observational study
}

\author{
Yoshitaka Nishikawa, ${ }^{1,2,3,4}$ Masaharu Tsubokura, ${ }^{3,4,5,6}$ Yoshimitsu Takahashi, ${ }^{1}$ \\ Shuhei Nomura, ${ }^{6,7,8}$ Akihiko Ozaki, ${ }^{6,9}$ Yuko Kimura, ${ }^{2,10}$ Tomohiro Morita, ${ }^{4}$ \\ Toyoaki Sawano, ${ }^{5,11}$ Tomoyoshi Oikawa, ${ }^{12}$ Takeo Nakayama ${ }^{1}$
}

To cite: Nishikawa Y,

Tsubokura M, Takahashi Y, et al. Change of access to emergency care in a repopulated village after the 2011 Fukushima nuclear disaster: a retrospective observational study. BMJ Open 2019:9:e023836. doi:10.1136/ bmjopen-2018-023836

- Prepublication history and additional material for this paper are available online. To view these files, please visit the journal online (http://dx.doi. org/10.1136/bmjopen-2018023836).

Received 27 April 2018 Revised 10 December 2018 Accepted 20 December 2018

D Check for updates

(C) Author(s) (or their employer(s)) 2019. Re-use permitted under CC BY-NC. No commercial re-use. See rights and permissions. Published by BMJ.

For numbered affiliations see end of article.

Correspondence to Dr Yoshitaka Nishikawa; ynishikawa-tky@umin.ac.jp

\section{ABSTRACT}

Objectives Sustaining emergency care access is of great concern. The aim of this study is to evaluate access to emergency care in a repopulated village following the 2011 Fukushima disaster.

Design This research was a retrospective observational study. The primary outcome measure was total emergency medical services (EMS) time. A Bayesian time series analysis was performed to consider local time series trend and seasonality.

Setting The residents in Kawauchi Village, Fukushima, Japan were forced to evacuate after the 2011 Fukushima disaster. As the radiation dose was an acceptable level, the residents began the process of repopulation in April 2012. Participants This study included patients transported by EMS from January 2009 to October 2015. Patients transported during the evacuation period (from March 2011 to March 2012) were excluded.

Results A total of 781 patients were transferred by EMS (281 patients before the disaster, 416 after repopulation and 84 during the evacuation period). A Bayesian time series analysis revealed an increase in total EMS time, from the first request call to arrival at a hospital of $21.85 \mathrm{~min}$ (95\% credible interval 14.2-29.0, Bayesian one-sided tail-area probability $\mathrm{p}=0.001$ ). After the disaster $42.3 \%$ of patients were transported to a partner hospital. Conclusions Total EMS time increased after repopulation of the area affected because of a massive number of hospital closures. Proactive partnerships would be a possible countermeasure in the affected areas after a major disaster.

\section{INTRODUCTION}

Equitable access should be pursued in healthcare services, ${ }^{1}$ as the disparity of access to the healthcare affects patients' outcomes. ${ }^{2-5}$ Access to healthcare is reportedly susceptible to patients' factors such as symptoms, severity, patients' values and preferences, financial burdens and geographical distance. ${ }^{67}$ Furthermore, there exist additional extrinsic factors, for example, sudden hospital closures, weather conditions and natural disasters. ${ }^{49}$
Strengths and limitations of this study

To the best of our knowledge, this 6-year retrospective observational study is the first to investigate the emergency care access in a repopulated rural area with abrupt hospital closures. We used emergency medical services (EMS) database of all EMS calls from the repopulated village.

- We used a Bayesian time series model to examine the change in total EMS time in the repopulated village.

- This study is limited because the EMS data lacked information on vital signs, mortality and patient outcomes.

- The observed findings may not be directly applicable to other settings, as this study only covered an evacuated municipality in Fukushima Prefecture.

In limited health resource areas, healthcare access is vulnerable to extrinsic factors. For example, it has been reported that access to haemodialysis care in rural areas was likely to be poorer than in urban areas due to fewer alternative facilities. ${ }^{10}$ It is crucial but challenging to sustain equity of rural healthcare access in the face of these factors.

Sustaining emergency care access in rural areas is of great concern. ${ }^{11}$ It has been reported that most rural trauma deaths occur before arrival at hospital. ${ }^{12}$ Japan's government reported that the nationwide mean total emergency medical services (EMS) time from the first request call to hospital arrival was $39.4 \mathrm{~min}$ in 2015 , yet there were patients taking more than $60 \mathrm{~min}$, especially in remote areas. ${ }^{13}$ In rural areas, health resources are limited and access is susceptible to extrinsic factors; it is not known how such extrinsic factors affect access, nor are there specific strategies to maintain access when extrinsic factors deteriorate healthcare facilities. 
In March 2011, an earthquake and tsunami struck the north-eastern area of Japan, and were followed by an accident at the Fukushima Daiichi Nuclear Power Plant (FDNPP). After the Fukushima disaster, residents of 12 municipalities, local government by each municipality unit (city, town and village) in Japan, near the FDNPP were forced to evacuate. ${ }^{6}$ A variety of health issues were highlighted after the disaster. ${ }^{14} 15$ Kawauchi Village, Fukushima, is located $12-30 \mathrm{~km}$ south-west of the FDNPP. Even before the Fukushima disaster, there was only a clinic for primary care $^{16}$; most emergency cases were transferred to outside hospitals belonging to the same medical zone (see online supplementary figure 1). As the postdisaster radiation dose of Kawauchi Village was at an acceptable level to live in, ${ }^{17}$ former residents started to return from April 2012. Kawauchi Village had originally limited health resources, and this was strongly affected by the disaster because most of the hospitals in Futaba District were forced to close. ${ }^{16}$

EMS time is one of the useful measures by which to assess emergency care access by local residents. ${ }^{12}{ }^{18}$ In Japan, Fire and Disaster Management Agency undertakes EMS including ambulance services. A local EMS governed by the Regional Fire Department in each medical zone is thus the sole public system to provide emergency transport for patients. ${ }^{19}$ When there are a limited number of nearby emergency hospitals available, particularly in remote areas, municipalities largely depend on EMS to transport emergency patients, as reported in the previous study. ${ }^{20}$ Thus, examining the EMS time of Kawauchi Village across the disaster is useful to assess the impact of the abrupt closure of emergency hospitals nearby on emergency care access in rural areas and consider countermeasures for such extrinsic factors.

The aim of this study is to evaluate the access to emergency medicine in rural areas affected by the Fukushima disaster. We hypothesised that there were changes in transport destination and EMS time between the periods before and after the disaster. We compared the EMS time using the transportation records of Kawauchi Village before the disaster to after repopulation.

\section{METHODS}

\section{Design, participants and setting}

This research is a retrospective observational study using data extracted from EMS transportation records collected by the EMS workers at Futaba Regional Fire Department. The inclusion criteria of this study were EMS calls requesting assistance from Kawauchi Village from January 2009 to October 2015. To evaluate the EMS time for residents in Kawauchi Village, we excluded patients during the mandatory evacuation period (from 11 March 2011 to 31 March 2012), because the backgrounds of these patients, who included reconstruction workers and public officials, did not live in the village and would introduce bias. Period 1 from 1 January 2009 to 10 March 2011 was defined as 'before disaster', and period
2 from 1 April 2012 to 31 October 2015 was defined as 'after repopulation'.

Kawauchi Village is located in a mountainous area $12-30 \mathrm{~km}$ south-west of FDNPP and was offered to evacuate by the Japanese government after the Fukushima disaster (see online supplementary figure 1). The former residents started returning to the village in April 2012, and 1684 of a total of 2746 residents before the disaster had returned to the village as of 1 October 2015 (see online supplementary figure 2). However, evacuation remains in force for areas with EMS hospitals in Futaba District, so access to healthcare remains suboptimal. ${ }^{16}{ }^{21}$ Many of the facilities (including four hospitals acceptable for EMS before the disaster) in Futaba District were forced to close (see online supplementary figure 2) ${ }^{22}$ Moreover, Kawauchi Village is designated as a remote area by the Japanese government. ${ }^{23}$ Remote areas are defined as regions with difficulty in securing medical care, such as mountainous regions, remote islands and depopulated areas. The plan for health and medical services in remote areas provided prefectural offices to support medical services in remote areas. In 2015, the population density of Kawauchi Village (10.20 people per $\left.\mathrm{km}^{2}\right)$ was lower than that of the national average (340.80 people per $\mathrm{km}^{2}$ ) and surrounding areas such as Koriyama City (443.00 people per $\mathrm{km}^{2}$ ), Iwaki City (284.30 people per $\mathrm{km}^{2}$ ) and Hirata Village (69.60 people per $\mathrm{km}^{2}$ ) (see online supplementary figure 1$).{ }^{21}$ Kawauchi National Health Insurance Clinic was the sole institution providing primary care in the village. Before the disaster, one fulltime physician managed all the patients who visited the clinic. After the disaster, the clinic closed for 1 year and resumed operations from April 2012 at the time of repopulation. A full-time physician and four part-time specialised doctors (a gastroenterologist, an orthopaedist, an ophthalmologist and a psychiatrist) work in the clinic. As previously reported, chronic diseases (eg, hypertension, dyslipidaemia and back pain) were the main causes of patients' visit. ${ }^{16}$ There are some walk-in patients with acute symptoms and transported emergency patients who have very mild symptoms.

In Futaba District, there were four emergency hospitals before the disaster. The hospitals did not have medical doctors serving exclusively at an emergency department. Each hospital operated a rota system for emergency care by medical doctors from other departments. The numbers of medical doctors in the four hospitals were 11, 11, 5 and 4 . The numbers of general beds for these four hospitals were 146, 120, 42 and 36. In Futaba District, there was a total of 75 medical doctors per 72822 residents before the disaster. ${ }^{24}$ After the disaster, these four hospitals were closed. In April 2018, Futaba Medical Center opened for emergency care in Futaba District. During this research period after repopulation, there were no hospitals in Futaba District accepting emergency patients from Kawauchi Village. In Hirata Village, there was one hospital that also used a rota system for emergency care before and after the disaster. Until 2014, one medical 
doctor was in charge of emergency care. Since then, two medical doctors have been working on weekends. In Koriyama City, there were four EMS hospitals before and after the disaster. One of the four hospitals was open for EMS. Among them, one tertiary hospital had two emergency medical doctors and four doctors (a physician, a surgeon, a paediatrician and a cardiologist) at night.

\section{Variables}

The primary outcome measure was total time from the initial EMS call to arrival at a hospital. Each time segment of total EMS time was divided as follows (see online supplementary figure 3): response time is time from the first EMS request to contact with the patient at the scene; on-scene time is time from contact to departure from the scene; and transport time is time from departure from the scene to arrival at a hospital. In cases of transport by emergency medical helicopter, the time when patients were delivered to emergency doctors in the helicopter is considered to be the time of arrival.

The following variables were collected in this study: sex; age; need for hospitalisation; severity (mild (no need for admission), moderate (need for admission for less than 3 weeks), severe (need for admission for periods more than or equal to 3 weeks) and death); number of hospitals called until accepted by a hospital; travel distance to the hospital from the scene $(\mathrm{km})$; locations of hospitals to which patients are transferred; distance to the hospital, time of day (daytime (08:0015:59), evening (16:00-23:59) and morning (00:00$07: 59)$ ); whether the incident occurred on a weekend or Japanese national holiday; season (spring (MarchMay), summer (June-August), autumn (SeptemberNovember) and winter (December-February)); and snow accumulation on the road (defined by Kawauchi Village). Need for hospitalisation was decided by the attending emergency room doctor based on the patient's severity. This study considered a total of 781 EMS calls from Kawauchi Village.

\section{Analytical methods}

Comparison of EMS time and patient characteristics

To compare EMS time and patient characteristics between periods 1 and 2, t-test was used for continuous variables and $\chi^{2}$ test for categorical variables.

\section{Bayesian time series analysis of total EMS time}

To evaluate the increase in total EMS time between periods 1 and 2 while considering local time series trend and seasonality, a Bayesian time series analysis was performed. Median total EMS time for each month from January 2009 to October 2015 was used as a time series data set. Using R V.3.3.2 (http://www.r-project. org) and CausalImpact package (Google LLC, California, USA), we created a state space model for the counterfactual prediction that no disaster or evacuation would occur using data from period 1, and causal impact was calculated by subtracting this from the observed data in period 2. ${ }^{25}$ Using a Markov chain Monte Carlo algorithm, we obtained point estimates and $95 \%$ credible intervals for the whole period. ${ }^{25}$ To test whether total EMS time increased after repopulation compared with that before the disaster, we calculated one-sided tail-area probability. To adjust for seasonal variations, 12-month periods were divided into four seasons.

\section{Comparison of facilities for transportation between period 1 and} period 2

We further compared the number and percentage of patients transported to each hospital between periods 1 and 2 in geographical terms. Facilities to which fewer than five patients were transported were omitted to protect the confidentiality of personal information.

\section{Multivariable analysis to assess the factors affecting total EMS} time after the disaster

A multivariable regression model was used to identify factors affecting total EMS time in period 1 and period 2. The objective variable was total EMS time, and the following variables that could affect total EMS time were included as explanatory variables: sex, age, need for hospitalisation, number of hospitals called, travel distance, time of day, whether the incident occurred on a weekend or national holiday and snow accumulation on the road. As the duration of hospitalisation (mild or moderate severity) was simply assumed by the attending emergency room doctor and was not necessarily the actual length of hospitalisation, we used need for hospitalisation. Season was excluded for multivariable analysis because snow accumulation, a major seasonal factor, was included. We assumed a negative binomial distribution, which could be used for count data with outliers. ${ }^{26}$ All complete cases were used for multivariable analyses.

Two-tailed $p$ values of $<0.05$ were considered significant. All statistical analyses were performed using $\mathrm{R}$ V.3.3.2 (http://www.r-project.org). Geospatial data were converted into longitude and latitude using Google Maps (Google LLC, California, USA), and plotted using ArcGIS V.10.2 (Esri Japan, Tokyo, Japan).

\section{Patient and public involvement}

The authors worked with Kawauchi Village government officers and EMS workers in the conceptualisation of this study and interpretation of the results. Beyond this, there was no patient or public involvement in this study.

\section{Ethics statement}

This study was approved.

\section{RESULTS}

\section{EMS time and patient characteristics}

There were 881 EMS calls in total from Kawauchi Village between January 2009 and October 2015. One hundred calls without a transport destination were excluded because patients were not delivered to a hospital (16 in 2009, 12 in 2010, 14 in 2011, 10 in 2012, 
Table 1 Emergency medical services time and patient characteristics of emergency medical service transport before the disaster and after repopulation

\begin{tabular}{|c|c|c|c|c|c|}
\hline \multirow[b]{2}{*}{ Emergency medical services time } & \multicolumn{2}{|c|}{$\begin{array}{l}\text { Before disaster } \\
(\mathrm{n}=281) \dagger\end{array}$} & \multicolumn{3}{|c|}{$\begin{array}{l}\text { After repopulation } \\
(\mathrm{n}=416) \ddagger\end{array}$} \\
\hline & Mean & SD & Mean & SD & $P$ value§ \\
\hline Total time (minutes) & 69.7 & 25.9 & 90.4 & 33.7 & $<0.001^{\star \star \star}$ \\
\hline Response time (minutes) & 11.0 & 7.0 & 10.2 & 7.3 & 0.145 \\
\hline On-scene time (minutes) & 17.0 & 10.0 & 21.6 & 12.3 & $<0.001^{\star \star \star}$ \\
\hline Transport time (minutes) & 41.7 & 21.5 & 58.6 & 27.2 & $<0.001^{\star \star \star}$ \\
\hline \multicolumn{6}{|l|}{ Patient characteristics } \\
\hline Continuous variable & Mean & SD & Mean & SD & \\
\hline Age (years old) & 70.4 & 19.7 & 68.6 & 20.5 & 0.25 \\
\hline Number of called hospitals & 1.9 & 1.8 & 1.8 & 1.5 & 0.50 \\
\hline Distance & 33.6 & 16.0 & 40.3 & 18.4 & $<0.001^{\star \star \star}$ \\
\hline Categorical variable & $\mathbf{n}$ & $\%$ & $\mathbf{n}$ & $\%$ & \\
\hline Sex & & & & & 0.07 \\
\hline Male & 140 & $49.8 \%$ & 238 & $57.5 \%$ & \\
\hline Female & 141 & $50.2 \%$ & 176 & $42.3 \%$ & \\
\hline Need for hospitalisation (+) & 180 & $64.1 \%$ & 241 & $57.9 \%$ & 0.12 \\
\hline Severity & & & & & 0.27 \\
\hline Mild (no need for hospitalisation) & 101 & $35.9 \%$ & 175 & $42.1 \%$ & \\
\hline $\begin{array}{l}\text { Moderate } \\
\text { (hospitalisation <3 weeks) }\end{array}$ & 133 & $47.3 \%$ & 185 & $44.5 \%$ & \\
\hline Severe (hospitalisation $\geqq 3$ weeks) & 38 & $13.5 \%$ & 41 & $9.9 \%$ & \\
\hline Death & 9 & $3.2 \%$ & 15 & $3.6 \%$ & \\
\hline Time of day & & & & & 0.73 \\
\hline Daytime (08:00-15:59) & 141 & $50.2 \%$ & 202 & $48.6 \%$ & \\
\hline Evening (16:00 pm-23:59) & 92 & $32.7 \%$ & 133 & $32.0 \%$ & \\
\hline Morning (00:00-07:59) & 48 & $17.1 \%$ & 81 & $19.5 \%$ & \\
\hline Season & & & & & 0.23 \\
\hline Spring & 66 & $23.5 \%$ & 93 & $22.4 \%$ & \\
\hline Summer & 68 & $24.2 \%$ & 111 & $26.7 \%$ & \\
\hline Autumn & 55 & $19.6 \%$ & 101 & $24.3 \%$ & \\
\hline Winter & 92 & $32.7 \%$ & 111 & $26.7 \%$ & \\
\hline Weekends or holidays (+) & 107 & $38.1 \%$ & 134 & $32.2 \%$ & 0.129 \\
\hline Snow accumulation (+) & 6 & $2.1 \%$ & 6 & $1.4 \%$ & 0.69 \\
\hline
\end{tabular}

Data were missing for distance (two patients in the before-disaster group and 16 in the after-repopulation group) and sex (0 and 2). †30 patients before disaster.

$\ddagger 56$ patients after repopulation, and 14 patients during the evacuation period were excluded.

$\S$ Significance codes: ${ }^{* * *}<0.001$.

13 in 2013,15 in 2014 and 20 in 2015). There were a total of 781 transported patients from Kawauchi Village (118 in 2009, 133 in 2010, 105 in 2011, 81 in 2012, 124 in 2013, 104 in 2014 and 116 in 2015). Eighty-four calls made during the evacuation period were excluded. There were 281 eligible EMS calls in period 1 and 416 in period 2 .

Table 1 describes the characteristics of EMS transport in periods 1 and 2 . There was a difference in mean total EMS time (69.7 vs 90.4 min, $\mathrm{p}<0.001)$. For the time segments, response time showed no significant difference ( 11.0 vs $10.2, \mathrm{p}=0.145$ ); on-scene time (17.0 vs 21.6, $\mathrm{p}<0.001)$ and transport time was different ( 41.7 vs 58.6, $\mathrm{p}<0.001)$. Figure 1 shows a time series plot of total EMS time. Comparison of patient characteristics shows that distance was the only significantly different variable between periods 1 and 2 (33.6 vs $40.3 \mathrm{~km}, \mathrm{p}<0.001)$. 


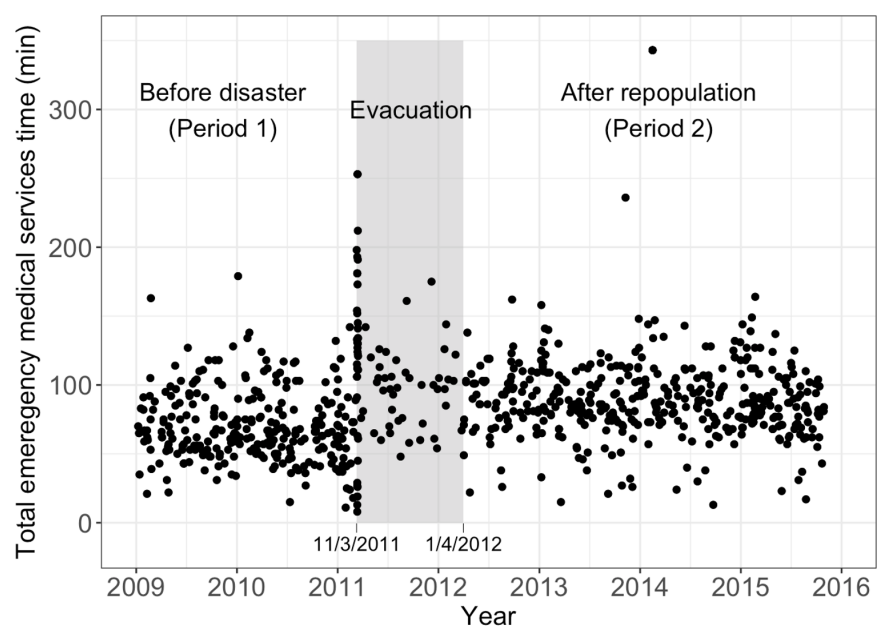

Figure 1 Time series plot of total emergency medical services time.

\section{Bayesian time series inference of causal impact of the disaster and evacuation on total EMS time}

Figure 2 shows the results of a time series analysis of the impact of the disaster and repopulation using monthly median of total EMS time. After repopulation, total EMS time had an average monthly median value of $88.6 \mathrm{~min}$. Using a Bayesian time series analysis, we would have expected a total EMS time in period 2 of $66.8 \mathrm{~min}(95 \%$ credible interval: $59.6-74.5 \mathrm{~min}$ ), in the counterfactual prediction that there was no disaster. Subtracting this prediction from the observed total EMS time yields an estimate of the significant increase of $21.9 \mathrm{~min}$ (95\% credible interval: 14.2-29.0 min) (Bayesian one-sided tail-area probability $\mathrm{p}=0.001$ ).
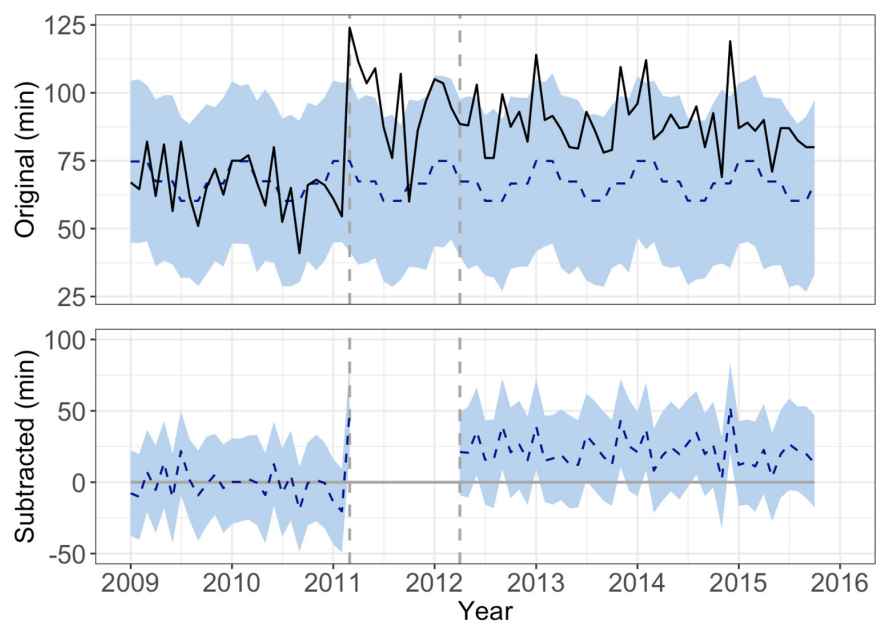

Figure 2 A Bayesian time series analysis using monthly median total emergency medical services time. The upper graphs show the original data (black line) and a counterfactual prediction of total emergency medical services time without the 2011 Fukushima disaster and subsequent evacuation (blue dotted line). The pointwise 95\% credible intervals are shown in light blue. The lower graph shows the difference between the observed data and counterfactual predictions (blue dotted line). Credible intervals are shown in light blue.
Changes in hospitals where the patients were transported Figure 3 describes the transport destinations in periods 1 and 2. Before the disaster, $80.4 \%$ of patients were transported to facilities in Futaba District (including 1.8\% to Kawauchi Village clinic). By contrast, with several closures of EMS hospitals following the disaster, $42.3 \%$ of patients were delivered to the hospital in Hirata Village and 29.6\% to Koriyama City.

\section{Multivariable analysis}

Table 2 shows the results of a multivariable analysis. A negative binomial generalised regression model revealed that the following factors were associated with the total EMS time. Before the disaster, the effects of weekends and holidays (estimate $5.9 \mathrm{~min}, \mathrm{p}=0.004$ ) compared with weekdays, number of hospitals called $(5.1 \mathrm{~min}$ per call, $\mathrm{p}<0.001)$ and distance $(10.1 \mathrm{~min}$ per $10 \mathrm{~km}$ increase, $\mathrm{p}<0.001)$ were significant. Although age also showed statistical significance, the coefficient was small (an age increase of 10 years corresponds to a $1 \mathrm{~min}$ increase). After repopulation, the effects of evening $(7.8 \mathrm{~min}, \mathrm{p}<0.001)$, morning $(12.9 \mathrm{~min}, \mathrm{p}<0.001)$, snow accumulation on the road (132.1 min, $\mathrm{p}<0.001$ ), number of called hospitals (6.7 min per call, $\mathrm{p}<0.001)$ and distance $(8.0 \mathrm{~min}$. per $10 \mathrm{~km}, \mathrm{p}<0.001$ ) were significant.

\section{DISCUSSION}

In the present study, we revealed that the total EMS time increased after the repopulation period compared with that before the disaster in Kawauchi Village. Yet, the destination of the EMS was secured through the shift of the main emergency care site from Futaba District to Hirata Village and Koriyama City following repopulation.

With a drastic change of access to emergency care, total EMS time was increased after repopulation. Among the three segments of total EMS time, transport time was the longest segment. There was an increase in transport time after the disaster with greater distances. The increased distance was associated with changes in transport destinations. A geographical comparison between two periods showed a drastic change of hospitals for patient transport before and after the disaster. First, there was an increase in the number of patients transported to Koriyama City, possibly because the residents tended to receive medical care in Koriyama City as Kawauchi Village's temporary evacuation shelter was located there. More importantly, $42.3 \%$ of all EMS patients transported were delivered to a hospital in Hirata Village after the disaster, while previously, no EMS patients had been accepted there. In the present case, Kawauchi Village developed a partnership with a hospital in Hirata Village before repopulation. It has been reported that there was a surge in the number of patients after disasters. ${ }^{27} 28$ Moreover, the distance to the hospital was associated with emergency patient distribution after the disaster. ${ }^{9}$ Although there was no sharp rise in the total number of ambulance calls after the disaster in the whole Fukushima,${ }^{29}$ there was a delay 


\section{Period 1 Before disaster $(\mathrm{N}=281) \quad$ Period 2 After repopulation $(\mathrm{N}=416)$ 2009/1/1 - 2011/3/10 2012/4/1 - 2015/10/31}
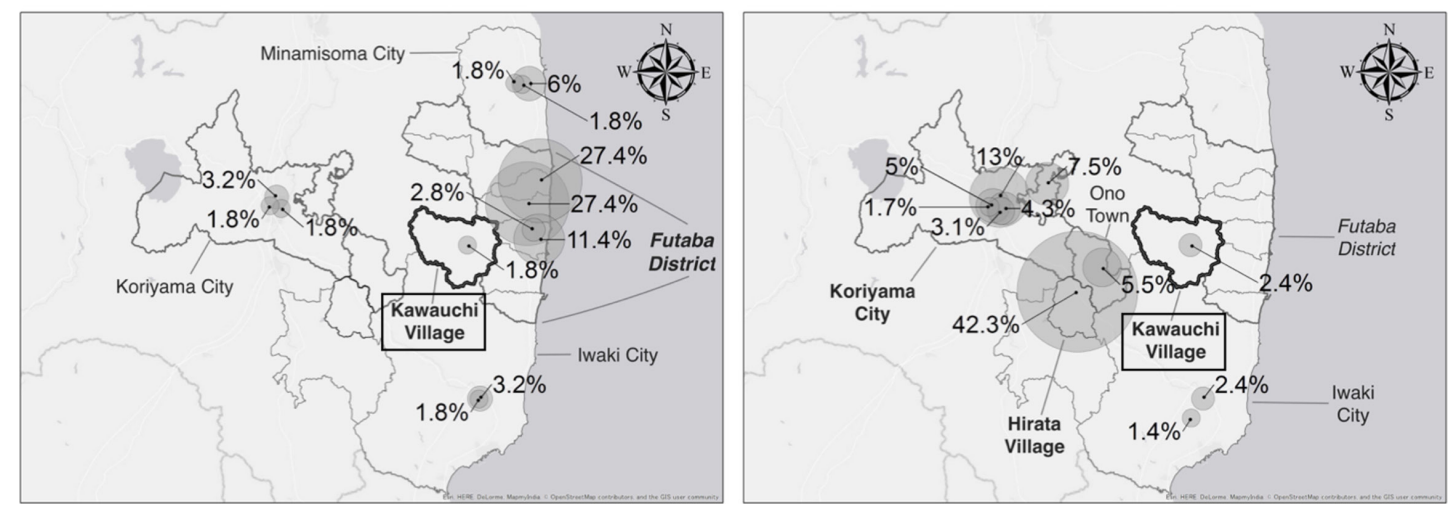

Figure 3 Changes in areas for patient transport before the disaster and after repopulation. The centre of each grey circle represents the location of transport facilities. The size of circles was in proportion to the percentage of transports of the total number in each period. Facilities to which fewer than five patients were transported were not shown to protect the confidentiality of personal information. In period $1,80.4 \%$ of patients were transported to hospitals in Futaba District. In period 2, $42.3 \%$ were transported to Hirata Village, and $29.6 \%$ to Koriyama City. During period 2, the four main emergency facilities in Futaba District were forced to close. The highway connecting the north (Minamisoma City) and the south coastal areas (Iwaki City) was closed because of the Fukushima Daiichi power plant incident throughout the research period. Source: Esri, HERE, DeLorme, MapmyIndia, (C) OpenStreetMap contributors, and the GIS user community.

in EMS transportation in the surrounding areas owing to the hospital closure. ${ }^{20}$ In rural areas, transport time would account for an important segment of total EMS time owing to the scarcity of hospitals. Proactive partnerships with a nearby hospital would thus be crucial for EMS transport in rural areas when the nearby facilities close abruptly.
Deciding the transport destination would be an important issue in limited-resource areas. As for the other two EMS time segments, on-scene time increased after the disaster while response time did not. Response time did not significantly change between the two periods, which was consistent with previous research immediately after the disaster. ${ }^{20}$ These results indicated that the initial performance of EMS

Table 2 Multivariable analysis for total emergency medical services time before the disaster and after repopulation

\begin{tabular}{|c|c|c|c|c|c|}
\hline & & Before disaster & & After repopulation & \\
\hline & & Estimates† (95\% Cl) & $P$ value $\ddagger^{*}$ & Estimates $(95 \% \mathrm{Cl})$ & $P$ value \\
\hline Constant§ & & $13.3(4.2$ to 22.8$)$ & $0.003^{* *}$ & 38.1 (30.0 to 46.6$)$ & $<0.001^{\star \star \star}$ \\
\hline Continuous variable & & & & & \\
\hline Age & & 0.1 (0.0 to 0.2$)$ & $0.045^{\star}$ & 0.1 (0.0 to 0.1$)$ & 0.21 \\
\hline Number of hospitals called & & 5.1 (3.5 to 6.8$)$ & $<0.001^{\star \star \star}$ & 6.7 (5.1 to 8.5$)$ & $<0.001^{\star \star \star}$ \\
\hline Distance (per 10 km) & & 10.1 (8.7 to 11.5$)$ & $<0.001^{\star \star \star}$ & $8(7.0$ to 9.0$)$ & $<0.001^{\star \star \star}$ \\
\hline Categorical variable & Reference & & & & \\
\hline Sex (Male) & Female & $3.3(-0.3$ to 7.0$)$ & 0.073 & $-3.4(-7.3$ to 0.5$)$ & 0.087 \\
\hline Need for hospitalisation (+) & $(-)$ & $1.3(-2.7$ to 5.2$)$ & 0.52 & $-1.9(-5.8$ to 2.0$)$ & 0.34 \\
\hline Time of day & & & & & \\
\hline Daytime (8:00 am-3:59 pm) & (Reference) & & & & \\
\hline $\begin{array}{l}\text { Evening (4:00 pm-23:59 } \\
\text { pm) }\end{array}$ & Daytime & $2.2(-2.0$ to 6.5$)$ & 0.31 & 7.8 (3.4 to 12.3$)$ & $<0.001^{\star \star \star}$ \\
\hline Morning (0:00 pm-7:59 am) & Daytime & $3.8(-1.3$ to 9.1$)$ & 0.16 & 12.9 (7.8 to 18.2$)$ & $<0.001^{* * *}$ \\
\hline Weekends or holidays & Weekdays & 5.9 (2.0 to 9.8$)$ & $0.004^{\star *}$ & $-0.5(-4.5$ to 3.6$)$ & 0.81 \\
\hline Snow accumulation (+) & $(-)$ & $-1.4(-11.6$ to 11.9$)$ & 0.8 & 132.1 (98.5 to 173.4$)$ & $<0.001^{\star * *}$ \\
\hline
\end{tabular}

†Minutes.

†Significance codes: ${ }^{* * *}<0.001,{ }^{* *}<0.01,{ }^{*}<0.05$.

$\S$ Constant: The value at which the regression line crosses the $y$-axis. 
did not change even after the disaster. However, an increase in on-scene time was observed after the disaster. A crucial element of increased on-scene time was deciding on a destination hospital prior to departure. ${ }^{18}$ Before the earthquake, EMS workers could depart for the coastal areas while calling hospitals, unless the patient required specialised treatment, as was the case in life-threatening medical emergencies or minor emergencies. ${ }^{30-32}$ It was suggested that the number of hospitals called before deciding on a destination hospital was associated with the increase in on-scene time $(6 \mathrm{~min}$ per call).$^{18}$ While there was no increase in the number of hospitals called after the disaster, it took longer to depart after repopulation than before the disaster. Regional collaborative efforts done before the disaster would be beneficial to limit the increase of on-scene time in limited-resource areas.

The impact of the demographic composition of Kawauchi Village on EMS time would be slight. It should be noted that only a few women with children returned to the village at first. In this study, the proportion of men tended to increase after repopulation compared with the population before the disaster, although the difference was not statistically significant. This male population would include local government officers and reconstruction workers. As repopulation progressed, $44.8 \%$ of the original population of elementary school children had returned to the village by May 2017. While the number of residents has gradually increased since 2012, the numbers of patients transported each year have remained similar throughout the research period. Moreover, although there have been changes in the demographic composition of Kawauchi Village, the effect of age or sex on EMS time was not found to be significant after repopulation. Thus, the impact of the age and sex of patients transported from Kawauchi Village on EMS capacity is likely to be marginal.

We further investigated the factors associated with total EMS time in each period. Before the disaster, weekends or holidays, number of hospitals called and distance were significant. After repopulation, time of day (evening and morning), snow accumulation on the road, number of hospitals called and distance were significant. Although comparison of different regression results provides limited information, it was important to improve access to emergency care in the affected areas, as shown by a survey. ${ }^{33}$ First, snow accumulation and geographical distance were factors associated with increased EMS time after the disaster. A previous report suggested that heavy snow deteriorated access to timely care around evacuation zones after the Fukushima disaster. ${ }^{34}$ The impact of snow accumulation may depend on travel distance in mountainous areas, as it showed significance only after the disaster with a transition of destination hospitals from coastal to mountainous areas. Road maintenance would be important to secure access to emergency care. Second, it should be noted that time of day (evening and morning) was associated with increased EMS time after repopulation but not before the disaster. As there were few alternative hospitals in the repopulation period, this point may become obvious at night-time. It is crucial to strengthen the EMS acceptance by hospitals at night-time to secure access to emergency care. In such areas, personnel and financial support should be considered to secure healthcare access. The government provided monetary support for hospitals in affected areas only during the period 20112016. However, in this case, there was no official personnel support for the hospital in Hirata Village after the repopulation of Kawauchi Village, while one physician helped in the inpatient wards of the hospital immediately after the disaster as part of the Disaster Medical Assistance Team. To secure access to emergency care, increasing medical staffing, particularly at night, should be considered in the long term after the disaster.

Several limitations of this study should be noted. First, the findings may not be directly applicable to other settings. Essentially, this study only covered an evacuated municipality in Fukushima Prefecture. Furthermore, the local geography and available health resources (eg, health facilities, health workers and medical equipment) would differ in other areas. For example, the available health resources could be more limited in low/middle-income countries, and it may be more challenging to find alternate facilities. However, to our knowledge, as this is the first municipality-level report regarding the repopulated areas after the Fukushima disaster, it would be valuable to understand changes in EMS time, changes in transport destinations and the factors that affect EMS time to enhance knowledge and preparedness for future disasters. Second, to ensure patient confidentiality, the final outcomes for individual patients cannot be ascertained by the regional fire department. Moreover, our data set did not include vital signs, as EMS workers only need to register vital signs for a limited number of severe symptoms. Finally, because the social or occupational backgrounds of patients were not collected, we could not know exactly which patients lived in the village. However, to avoid the inclusion of non-villagers as long as possible, we excluded the patients during the mandatory evacuation period.

In conclusion, total EMS time increased after repopulation compared with that before the disaster, and there was a drastic change in transport destinations because of extensive hospital closures. A partnership hospital located in Hirata Village accepted $42.3 \%$ of patients and was closer than the nearest urban areas. Proactive partnerships would be possible countermeasures in the affected areas after a major disaster .

\section{Author affiliations}

${ }^{1}$ Department of Health Informatics, Kyoto University School of Public Health, Kyoto, Kyoto, Japan

${ }^{2}$ Department of Internal Medicine, Kawauchi Village National Health Insurance Clinic, Futaba-gun, Fukushima, Japan

${ }^{3}$ Department of Internal Medicine, Hirata Central Hospital, Ishikawa-gun,

Fukushima, Japan

${ }^{4}$ Department of Internal Medicine, Soma Central Hospital, Soma, Fukushima, Japan ${ }^{5}$ Department of Public Health, Fukushima Medical University School of Medicine,

Fukushima, Fukushima, Japan

${ }^{6}$ Research Center for Community Health, Minamisoma Municipal General Hospital, Minamisoma, Fukushima, Japan

${ }^{7}$ Department of Epidemiology and Biostatistics, School of Public Health, Imperial College London, London, UK 
${ }^{8}$ Department of Global Health Policy, Graduate School of Medicine, The University of Tokyo, Tokyo, Japan

${ }^{9}$ Teikyo University Graduate School of Public Health, Tokyo, Japan

${ }^{10}$ Department of Radiation Health Management, Fukushima Medical University

School of Medicine, Fukushima, Fukushima, Japan

${ }^{11}$ Department of Surgery, Minamisoma Municipal General Hospital, Minamisoma,

Fukushima, Japan

${ }^{12}$ Department of Neurosurgery, Minamisoma Municipal General Hospital,

Minamisoma, Fukushima, Japan

Acknowledgements The authors express sincere gratitude to all the staff of Futaba Regional Fire Department, the staff of all the transport facilities and the staff in the Kawauchi Village Office for data collection on patient care, and to Mr Masatsugu Tanaki of Minamisoma Municipal General Hospitals for data management and technical support. We also thank the members of Department of Therapeutic Oncology, Kyoto University Graduate School of Medicine (Professor Manabu Muto) for insightful suggestions.

Contributors Conception and design: YN, MT and TN; data collection and management: YN, MT, AO, YK, TM, TS and T0; data analysis: YN, YT and SN; interpretation of the results: all authors; drafting of the article: $\mathrm{YN}$; critical revision of the article for important intellectual content: all authors; final approval of the article: all the authors.

Funding This work was partly supported by Institute of Medical Care and Societal Health. YN was supported by the 2016 Kyoto University School of Public Health Super Global Course's travel scholarship to the United Kingdom through the Top Global University Project 'Japan Gateway: Kyoto University Top Global Program', sponsored by the Ministry of Education, Culture, Sports, Science and Technology (MEXT), Japan.

Disclaimer These funders played no role in this study.

Competing interests None declared.

Patient consent for publication Not required.

Ethics approval Ethics Board of Minamisoma Municipal General Hospital, the Ethics Committee of the Kyoto University Graduate School of Medicine, and Fukushima Medical University Certified Review Board.

Provenance and peer review Not commissioned; externally peer reviewed.

Data sharing statement № additional data available.

Open access This is an open access article distributed in accordance with the Creative Commons Attribution Non Commercial (CC BY-NC 4.0) license, which permits others to distribute, remix, adapt, build upon this work non-commercially, and license their derivative works on different terms, provided the original work is properly cited, appropriate credit is given, any changes made indicated, and the use is non-commercial. See: http://creativecommons.org/licenses/by-nc/4.0/.

\section{REFERENCES}

1. Oliver A, Mossialos E. Equity of access to health care: outlining the foundations for action. J Epidemiol Community Health 2004;58:655-8

2. Onega T, Duell EJ, Shi X, et al. Geographic access to cancer care in the U.S. Cancer 2008;112:909-18.

3. Klein MB, Kramer CB, Nelson J, et al. Geographic access to burn center hospitals. JAMA 2009;302:1774-81.

4. Chan L, Hart LG, Goodman DC. Geographic access to health care for rural Medicare beneficiaries. J Rural Health 2006;22:140-6.

5. Alter DA, Naylor CD, Austin P, et al. Effects of socioeconomic status on access to invasive cardiac procedures and on mortality after acute myocardial infarction. N Engl J Med 1999;341:1359-67.

6. Ochi S, Tsubokura M, Kato S, et al. Hospital Staff Shortage after the 2011 Triple Disaster in Fukushima, Japan-An Earthquake, Tsunamis, and Nuclear Power Plant Accident: A Case of the Soso District. PLoS One 2016;11:e0164952.

7. Shen YC, Hsia RY. Changes in emergency department access between 2001 and 2005 among general and vulnerable populations. Am J Public Health 2010;100:1462-9.

8. Onitilo AA, Liang $H$, Stankowski RV, et al. Geographical and seasonal barriers to mammography services and breast cancer stage at diagnosis. Rural Remote Health 2014;14:1-12.

9. Lee DC, Smith SW, Carr BG, et al. Redistribution of Emergency Department Patients After Disaster-Related Closures of a Public
Versus Private Hospital in New York City. Disaster Med Public Health Prep 2015;9:256-64.

10. Stephens JM, Brotherton S, Dunning SC, et al. Geographic disparities in patient travel for dialysis in the United States. J Rural Health 2013;29:n/a-348.

11. Kim JY, Farmer P, Porter ME. Redefining global health-care delivery. Lancet 2013;382:1060-9.

12. Newgard CD, Fu R, Bulger E, et al. Evaluation of Rural vs Urban Trauma Patients Served by 9-1-1 Emergency Medical Services. JAMA Surg 2017;152:11.

13. Japan Fire and Disaster Management Agency. The 2016 white paper [in Japanese]. 2016 http://www.fdma.go.jp/neuter/topics/fieldList9_3. html

14. Nishikawa Y, Tsubokura M, Kato S, et al. Possible Anisakiasis Associated with Fishery Resumption. Disaster Med Public Health Prep 2014;8:117-8.

15. Nishikawa Y, Fukuda $Y$, Tsubokura M, et al. Managing Type 2 Diabetes Mellitus through Periodical Hospital Visits in the Aftermath of the Great East Japan Earthquake Disaster: A Retrospective Case Series. PLoS One 2015;10:e0125632.

16. Nishikawa Y, Tsubokura M, Yamazaki S. Healthcare Delivery to a Repopulated Village after the Fukushima Nuclear Disaster: A Case of Kawauchi Village, Fukushima, Japan. Japan Med Assoc J 2016;59:159-61.

17. Tsubokura M, Kato S, Nihei M, et al. Limited internal radiation exposure associated with resettlements to a radiation-contaminated homeland after the Fukushima Daiichi nuclear disaster. PLoS One 2013;8:e81909-7.

18. Hanaki N, Yamashita K, Kunisawa S, et al. Effect of the number of request calls on the time from call to hospital arrival: a crosssectional study of an ambulance record database in Nara prefecture, Japan. BMJ Open 2016;6:e012194.

19. Tanigawa K, Tanaka K. Emergency medical service systems in Japan: past, present, and future. Resuscitation 2006:69:365-70.

20. Morita T, Tsubokura M, Furutani T, et al. Impacts of the 2011 Fukushima nuclear accident on emergency medical service times in Soma District, Japan: a retrospective observational study. BMJ Open 2016;6:e013205.

21. Japan Medical Association. Japan Medical Analysis Platform. 2015. http://jmap.jp

22. Ozaki A, Shimada Y, Yamamoto K, et al. Death of the sole doctor at Takano Hospital 6 years after the Fukushima nuclear crisis-who is responsible for health care delivery in the Fukushima disaster zone? QJM 2018;111:79-81.

23. Medical Services in Remote Areas. Ministry of health, labour and welfare. https://www.mhlw.go.jp/english/wp/wp-hw5/dl/23010214e. pdf

24. Fukushima Prefecture. Fukushima prefectural sixth medical care plan. https://www.pref.fukushima.lg.jp/uploaded/attachment/1113. pdf

25. Brodersen $\mathrm{KH}$, Gallusser F, Koehler J, et al. Inferring causal impact using Bayesian structural time-series models. Ann Appl Stat 2015:9:247-74

26. Zeileis A, Kleiber C, Jackman S. Regression Models for Count Data in R. J Stat Softw 2008;27:1-25.

27. Eastman AL, Rinnert KJ, Nemeth IR, et al. Alternate site surge capacity in times of public health disaster maintains trauma center and emergency department integrity: Hurricane Katrina. J Trauma 2007;63:253-7.

28. Adalja AA, Watson M, Bouri N, et al. Absorbing citywide patien surge during hurricane sandy: A case study in accommodating multiple hospital evacuations. Ann Emerg Med 2014;64:66-73.

29. Fukuma S, Ahmed S, Goto R, et al. Fukushima after the great east japan earthquake: Lessons for developing responsive and resilient health systems. J Glob Health 2017;7:1-8.

30. Keeley EC, Boura JA, Grines CL. Primary angioplasty versus intravenous thrombolytic therapy for acute myocardial infarction: a quantitative review of 23 randomised trials. Lancet 2003;361:13-20.

31. Giles MF, Rothwell PM. Risk of stroke early after transient ischaemic attack: a systematic review and meta-analysis. Lancet Neurol 2007;6:1063-72.

32. Freeman J, Nicholl J, Turner J. Does size matter? The relationship between volume and outcome in the care of major trauma. $J$ Health Serv Res Policy 2006;11:101-5.

33. Reconstruction Agency. Kawauchi village residents' opinion survey. 2016 http://www.reconstruction.go.jp/topics/main-cat1/sub-cat1-4/ ikoucyousa/27ikouchousakekka kawauchi.pdf.

34. Nishikawa Y, Ozawa Y, Tsubokura M, et al. Long-term vulnerability of access to hemodialysis facilities in repopulated areas after the Fukushima Nuclear Disaster: a case report. Oxf Med Case Reports 2018;2018:228-30. 